\title{
Observation of Suprathermal Flux from SROSS-C2 Data at Low Latitude
}

\author{
Rama Shankar Pandey ${ }^{1}$ and Krishan Datta Misra ${ }^{2}$ \\ ${ }^{1}$ Department of Physics, Amity School of Engineering, Amity University Uttar Pradesh, Sector-125, Noida 201301, India \\ ${ }^{2}$ Department of Applied Physics, Institute of Technology, Banaras Hindu University, Varanasi 221005, India
}

Correspondence should be addressed to Rama Shankar Pandey, rspandey@ase.amity.edu

Received 28 October 2008; Accepted 28 December 2008

Recommended by Eric G. Blackman

The studies of suprathermal flux at equatorial latitude for low solar activity year of 1996 (from January to December) are reported. The retarding potential analyzer (RPA) data of Indian space research organization Stretched Rohini Satellite Series-C2 (SROSSC2) are used. The suprathermal electron flux data are chosen in the height range of $475 \pm 50 \mathrm{~km}$. Seasional, latitudinal, and height variations of suprathermal flux having energy range above $30 \mathrm{eV}$ along with comparisons in latitudinal variation of small energy superathermal flux of $5 \mathrm{eV}$ are also reported. The data are selected during the period of local midnight to avoid contaminations from photoelectron flux and flux coming from coating of electrodes.

Copyright ( 2009 R. S. Pandey and K. D. Misra. This is an open access article distributed under the Creative Commons Attribution License, which permits unrestricted use, distribution, and reproduction in any medium, provided the original work is properly cited.

\section{Introduction}

The majority of photoelectrons produced by the ionization of atmospheric neutral particles by solar ultraviolet radiations have energies ranging from a few $\mathrm{eV}$ up to about $60 \mathrm{eV}$ [1-3]. Observations on suprathermal electron flux and electron temperature at high latitudes were studied using Explorer 33 for energy range of $5 \mathrm{eV}$ to $200 \mathrm{eV}$ [4]. Furthermore, they extended their study to latitude passes at $1.2<L<2.5[5]$.

Although most of the photoelectrons are produced below about $300 \mathrm{~km}$ and lose their energy locally through elastic and inelastic collisions with neutrals, photoelectrons produced above that level and those reaching that level from below can escape the local ionosphere and travel along the geomagnetic field lines. Coates et al. [6] found that energy spectra of low-energy field-aligned fluxes observed by suprathermal explorer (AE) satellite are at an altitude of $350 \mathrm{~km}$ at high latitudes. As the field-aligned fluxes are turned on at dawn, the conjugate hemisphere becomes sunlit. It was further observed that field-aligned flows of electrons below $100 \mathrm{eV}$ observed at geosynchronus orbit were the photoelectrons, reaching from the ionosphere. Suprathermal electrons were observed by tethered satellite system (TSS$1 \mathrm{R})$ and moderate solar activity (MSA) satellite in the range of $70 \mathrm{eV}$ and $50 \mathrm{eV}$ at corresponding height $20 \mathrm{~km}$ away from earth and $200 \mathrm{~km}$ altitude, respectively [7, 8]. None has reported till so far detail variations near equatorial latitudes.

Recently, the suprathermal flux was first seen in RPA data mounted on Stretched Rohini Satellite Series-C2 (SROSSC2) Satellite at equatorial and very low latitude region of the ionosphere ranging in energy range of few $\mathrm{eV}$ to $50 \mathrm{eV}$. The data are obtained from the retarding potential analyzer (RPA) on board of the Indian low-earth orbiting satellite SROSS-C2 [9, 10]. An estimate of scintillation indices based on the in site density measurements compares well with the ground-based measurements. The bubble development on this night during a low solar activity period was attributed to promote penetration event. Niranjan et al. [11] have investigated, based on ionosonde $630.0 \mathrm{~nm}$ airglow photometer and SROSS-C2 satellite data revealed, that seasonal variation of the occurrence and probable onset times of the post-midnight spread-F during the summer solstice months of low solar activity period both depend on the characteristics of the highly variable Equatorial Mid night temperature Maximum Phenomena.

Therefore, in this paper, the measurements of the suprathermal electron flux made with the electron RPA onboard of the SROSS-C2 satellite, during low solar activity 


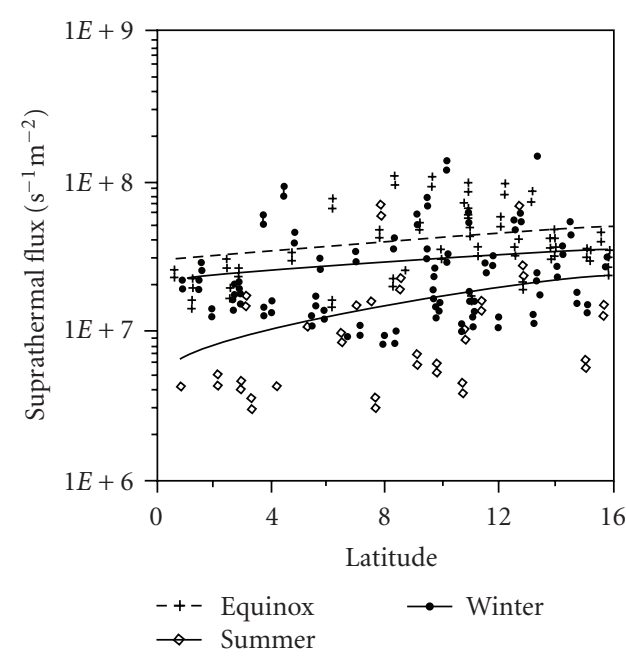

(a)

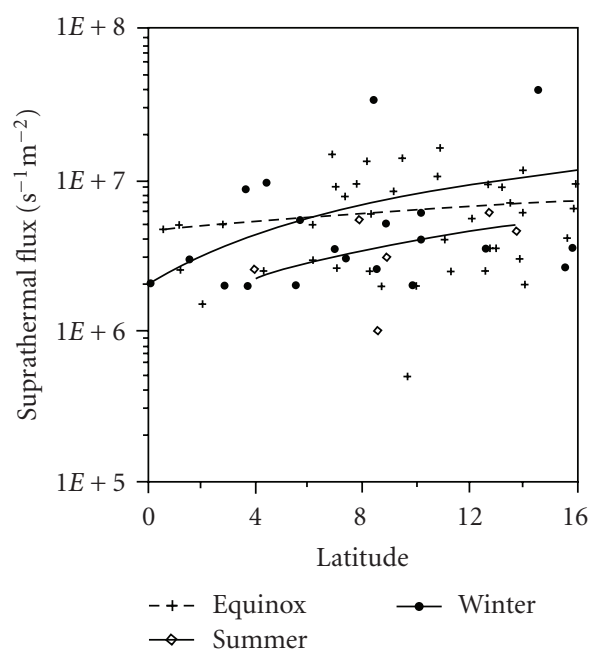

(b)

FIGURE 1: Seasional variations of superathermal flux with latitudes (a) at energy $32 \mathrm{eV}$ and (b) at energy $5 \mathrm{eV}$. The others fixed parameters are shown in Table 1.

TABLE 1

\begin{tabular}{lccc}
\hline Parameters & Summer & Winter & Equinox \\
\hline UT & $17: 28-19: 58$ & $17: 21-19: 47$ & $17: 1-19: 41$ \\
Height & $447 \mathrm{~km}-510 \mathrm{~km}$ & $429 \mathrm{~km}-482 \mathrm{~km}$ & $428 \mathrm{~km}-460 \mathrm{~km}$ \\
Theta & $4^{\circ}-18^{\circ}$ & $4^{\circ}-19^{\circ}$ & $1^{\circ}-18^{\circ}$ \\
Longitude & $62^{\circ}-91^{\circ}$ & $69^{\circ}-91^{\circ}$ & $66^{\circ}-91^{\circ}$ \\
\hline
\end{tabular}

TABLE 2

\begin{tabular}{lccc}
\hline Parameters & Summer & Winter & Equinox \\
\hline UT & $17: 52-18: 10$ & $17: 0-17: 46$ & $17: 19-18: 41$ \\
Height & $428 \mathrm{~km}-469 \mathrm{~km}$ & $465 \mathrm{~km}-480 \mathrm{~km}$ & $429 \mathrm{~km}-500 \mathrm{~km}$ \\
Theta & $5^{\circ}-18^{\circ}$ & $8^{\circ}-16^{\circ}$ & $3^{\circ}-18^{\circ}$ \\
Longitude & $69^{\circ}-84^{\circ}$ & $90^{\circ}-93^{\circ}$ & $71^{\circ}-90^{\circ}$ \\
\hline
\end{tabular}

year of 1996, are being reported. The high-energy tail in electron RPA, I-V characteristic, when the retardation voltage is made more negative than about $-1 \mathrm{~V}$, is due to the suprathermal electrons. During daytime, the suprathermal currents are at least an order of magnitude higher than the nighttime values because of the other contamination produced by photoelectron flux, which dominates the daytime values. In the SROSS-C2 experiment, a retardation voltage of up to $32 \mathrm{eV}$ has been used. With a retardation voltage of $32 \mathrm{eV}$, the probe measures the integral flux of suprathermal electrons of energies above $32 \mathrm{eV}$. In the present study, only the midnight time data covering the period from January 1996 to December 1996 have been used. During this period, the satellite altitude remained between $420 \mathrm{~km}$ to $620 \mathrm{~km}$. Latitudinal, seasional, and altitude variations of nighttime purely uncontaminated suprathermal flux are being reported at equatorial latitudes.

\section{Data}

The SROSS-C2 satellite was of octagonal prismoid shape with eight body-mounted solar panels on the eight sides of the prismoid. SROSS-C2 satellite data were processed for the period of January 1996 to December 1996. This satellite has perigee, at $450 \mathrm{~km}$ and apogee, at $650 \mathrm{~km}$ with inclination of $45^{\circ}$. Retarding potential analyzer is mounted on the satellite with magnetic angle, $130^{\circ}$ and sun angle $90^{\circ}-$ $120^{\circ}$. In the SROSS-C2 experiment, a retardation voltage of up to $32 \mathrm{eV}$ has been used. Retarding potential analyzer planar ion traps are in the $X$ and $Z$ direction and $X$ axis is inclined to $20^{\circ}$ to the velocity vector. The data represents midnight position where only purely suprathermal electrons are recorded. The period of year 1996 January to December is divided for seasonal variation into winter, equinox, and summer months. The data were selected for small range of values of longitudes, velocity vector, and local times suited to local midnight period.

\section{Result and Discussion}

Figure 1(a) shows the variation of suprathermal flux with latitude near midnight UT 17:40 19:40 and local time 22:32 23:30 in the height range $425 \sim 500 \mathrm{~km}$ and longitude range $64^{\circ} \sim 88^{\circ}$, also $\theta=4^{\circ} \sim 18^{\circ}$ during summer, winter, and equinox where as other details are shown in Table 1 . The suprathermal flux shows the seasonal variation with latitude in Figure 1(a). It is maximum during equinox month and minimum during summer month and in winter slightly less than equinox. Figure 1(b) shows the latitudinal profiles of $5 \mathrm{eV}$ range of suprathermal flux during summer, winter, and equinox months. The other fixed parameters are given in Table 2. The suprathermal flux at $5 \mathrm{eV}$ is one order of magnitude less than that at $32 \mathrm{eV}$. At $5 \mathrm{eV}$, the flux is more in equinox and winter months than in summer. This aspect conforms the observation of Wrenn et al. [12], showing increase at $32 \mathrm{eV}$ and decrease of suprathermal flux at $5 \mathrm{eV}$. Suprathermal electrons created in the ionosphere below $250 \mathrm{~km}$ lose their energy locally due to high-density neutral particles bringing the distribution function close to two component distribution. The cold component of 


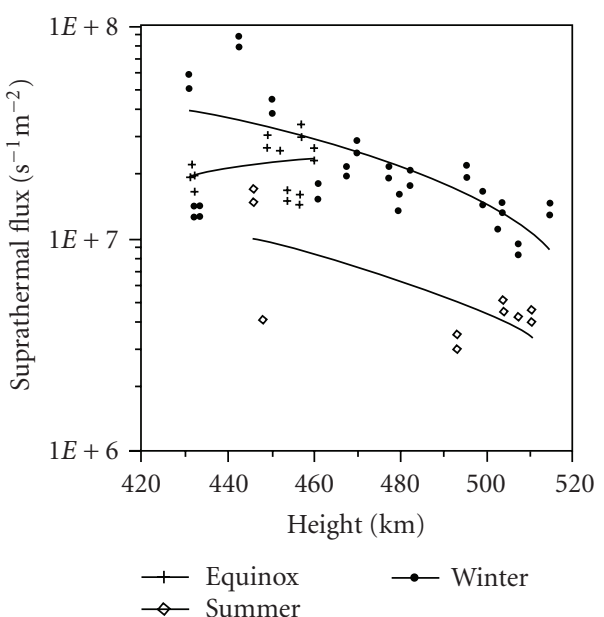

FIGURE 2: Seasional variation of superathermal flux with height at energy $32 \mathrm{eV}$, latitude range $\left(0^{\circ}-5^{\circ}\right)$. The others fixed parameters are shown in Table 3.

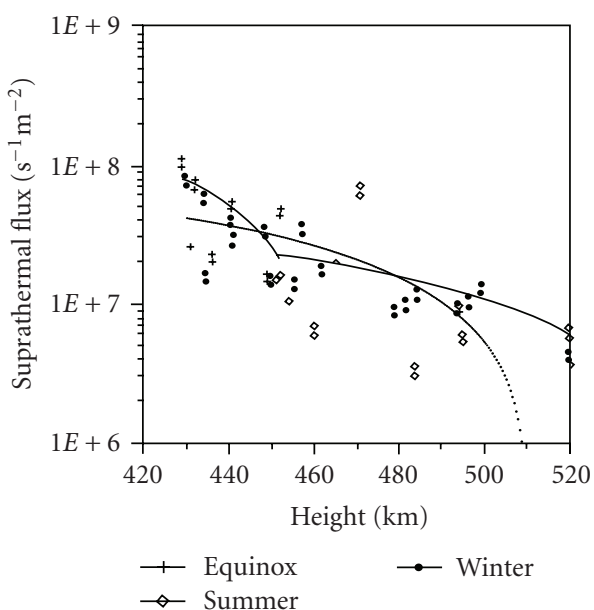

Figure 3: Seasional variation of superathermal flux with height at energy $32 \mathrm{eV}$, latitude range $\left(5^{\circ}-10^{\circ}\right)$. The others fixed parameters are shown in Table 4.

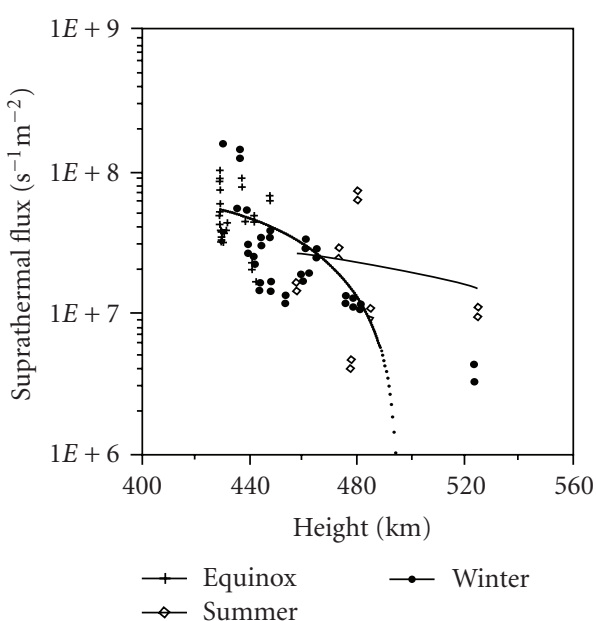

Figure 4: Seasional variation of superathermal flux with height at energy $32 \mathrm{eV}$, latitude range $\left(10^{\circ}-15^{\circ}\right)$. The others fixed parameters are shown in Table 5.
TABle 3

\begin{tabular}{lccc}
\hline Parameters & Summer & Winter & Equinox \\
\hline UT & $18: 54-19: 39$ & $17: 22-19: 22$ & $17: 0-19: 29$ \\
Latitude & $0^{\circ}-5^{\circ}$ & $0^{\circ}-5^{\circ}$ & $0^{\circ}-5^{\circ}$ \\
Theta & $3^{\circ}-19^{\circ}$ & $4^{\circ}-19^{\circ}$ & $5^{\circ}-18^{\circ}$ \\
Longitude & $62^{\circ}-78^{\circ}$ & $70^{\circ}-88^{\circ}$ & $71^{\circ}-82^{\circ}$ \\
\hline
\end{tabular}

TABLE 4

\begin{tabular}{lccc}
\hline Parameters & Summer & Winter & Equinox \\
\hline UT & $17: 30-19: 53$ & $17: 53-19: 46$ & $17: 0-17: 32$ \\
Latitude & $5^{\circ}-10^{\circ}$ & $5^{\circ}-10^{\circ}$ & $5^{\circ}-10^{\circ}$ \\
Theta & $4^{\circ}-17^{\circ}$ & $2^{\circ}-19^{\circ}$ & $12^{\circ}-18^{\circ}$ \\
Longitude & $71^{\circ}-91^{\circ}$ & $70^{\circ}-90^{\circ}$ & $75^{\circ}-87^{\circ}$ \\
\hline
\end{tabular}

TABle 5

\begin{tabular}{lccc}
\hline Parameters & Summer & Winter & Equinox \\
\hline UT & $17: 44-19: 51$ & $17: 53-19: 13$ & $17: 1-18: 56$ \\
Latitude & $10^{\circ}-15^{\circ}$ & $10^{\circ}-15^{\circ}$ & $10^{\circ}-15^{\circ}$ \\
Theta & $4^{\circ}-18^{\circ}$ & $4^{\circ}-14^{\circ}$ & $12^{\circ}-19^{\circ}$ \\
Longitude & $70^{\circ}-89^{\circ}$ & $72^{\circ}-82^{\circ}$ & $71^{\circ}-89^{\circ}$ \\
\hline
\end{tabular}

electrons $<100 \mathrm{eV}$ has its greatest temperature near local midnight, which gradually decreases in the morning sector. Furthermore, it has also been reported [13] that the sharp ionization peak in photoionization in the energy rang $25-$ $30 \mathrm{eV}$ and characteristic troughs at energies less than $4 \mathrm{eV}$ are associated with large cross-section of the vibrational excitation of molecular nitrogen. The suprathermal fluxes are having a positive corelation with equatorial anomaly, normally observed in density variation. The electron production rate dependens on concentration ratio of $\mathrm{O}^{+} / \mathrm{O}_{2}$, whereas loss rate is controlled by ratio of $\mathrm{O}^{+} / \mathrm{N}_{2}$. This ratio was reported at $300 \mathrm{~km}$ to be three times higher in winter months than in summer months $[14,15]$. The change in composition has been attributed to the pattern of global circulation in thermosphere. In this case, SROSS-C2 data, also shows the small increase in winter than in summer. For equinox period, it is two times higher than summer months. In

Figure 2, the height variation of suprathermal flux obtained from SROSS-C2 satellite between latitude range $\left(0^{\circ}-5^{\circ}\right)$ and longitude range $60^{\circ}-78^{\circ}$ and for other fixed parameters as shown in Table 3 are given for winter summer and equinox months. The suprathermal flux is more in summer and decreases with height except during the month of equinox where suprathermal flux shows minimum increase with height. The change and increase in superathermal flux may be due to the principle of electrodynamics lifting at equator. The $\mathbf{E} \times \mathbf{B}$ field at the equator may enhance not only the density flux but also suprethermal fluxes. Furthermore, this may also be the remnant part of suprathermal flux, even after photoionization, still not reaching to thermal equilibrium due to horizontal transport mechanism reaching from dayside to nightside from mid latitude to low equatorial latitude $[3,13]$. The fountain effect reported shows higher density at equator and decreases further away from equator. 
Similar variations in suprathermal flux show their maximum at equator and further decrease away from equator [16]. The height variation of suprathermal at latitude range of $\left(5^{\circ}-\right.$ $\left.10^{\circ}\right)$ in Figure 3 and fixed parameters are given in Table 4 showing similar decreasing trend from equinox, summer, and winter away from equator. This decreasing aspect is further extended up to $\left(10^{\circ}-15^{\circ}\right)$ latitude as shown in Figure 4 and Table 5, this might be associated with equatorial anomaly.

\section{Conclusion}

The suprathermal flux is more at equator and decreases away from equator. The flux is maximum during equinox months than summer months. The electrodynamics lifting and fountain effects are seen and are conforming to the present data. The flux is an order of magnitude higher at $32 \mathrm{eV}$ than those at $5 \mathrm{eV}$.

\section{References}

[1] H. E. Hinteregger, "Combined retarding potential analysis of photoelectrons and environmental charged particles up to 234 km," Space Research, vol. 1, pp. 304-327, 1960.

[2] A. Dalgarno, M. B. McElroy, and R. J. Moffett, "Electron temperatures in the ionosphere," Planetary and Space Science, vol. 11 , no. 5 , pp. 463-484, 1963.

[3] T. Tohmatsu, T. Ogawa, and H. Tsuruta, "Photoelectronic processes in the upper atmosphere-I: energy apectrum of the primary photoelectrons," Report of Ionosphere and Space Research in Japan, vol. 19, pp. 482-508, 1965.

[4] E. J. Maier and B. C. Narasinga Rao, "Observations of the superathermal electron flux and the electron temperature at high latitudes," Journal of Geophysical Research, vol. 75, no. 34, pp. 7168-7174, 1970.

[5] B. C. Narasinga Rao and E. J. Maier, "Photoelectron flux and protonospheric heating during the conjugate point sunrise," Journal of Geophysical Research, vol. 75, no. 4, pp. 816-822, 1970.

[6] A. J. Coates, A. D. Johnstone, J. J. Sojka, and G. L. Wrenn, "Ionospheric photoelectrons observed in the magnetosphere at distances up to 7 earth radii," Planetary and Space Science, vol. 33, no. 11, pp. 1267-1275, 1985.

[7] J. D. Winningham, N. H. Stone, C. A. Gurgiolo, K. H. Wright, R. A. Frahm, and C. A. Bonifazi, "Suprathermal electrons observed on the TSS-1R satellite," Geophysical Research Letters, vol. 25, no. 4, pp. 429-432, 1998.

[8] K. Spenner, W. C. Knudsen, and W. Lotze, "Suprathermal electron fluxes in the Venus nightside ionosphere at moderate and high solar activity," Journal of Geophysical Research E, vol. 101, no. E2, pp. 4557-4563, 1996.

[9] A. Paul, S. Ray, A. DasGupta, and S. C. Garg, "First in situ observations of equatorial ionospheric bubbles by Indian satellite SROSS-C2 and simultaneous multisatellite scintillations," Radio Science, vol. 37, no. 5, pp. 1087-1094, 2002.

[10] R. Sekar and D. Chakrabarty, "Equatorial spread-F research in India: a brief review," Indian Journal of Radio \& Space Physics, vol. 37, no. 1, pp. 7-27, 2008.

[11] K. Niranjan, P. S. Brahmanandam, P. Ramakrishna Rao, G. Uma, D. S. V. V. D. Prasad, and P. V. S. Rama Rao, "Post midnight spread-F occurrence over Waltair $\left(17.7^{\circ} \mathrm{N}, 83.3^{\circ}\right.$ E) during low and ascending phases of solar activity," Annales Geophysicae, vol. 21, no. 3, pp. 745-750, 2003.
[12] G. L. Wrenn, J. F. E. Johnson, and J. J. Sojka, "Stable 'pancake' distributions of low energy electrons in the plasma trough," Nature, vol. 279, no. 5713, pp. 512-514, 1979.

[13] G. V. Khazanov, T. Neubert, and G. D. Gefan, "A unified theory of ionosphere-plasmasphere transport of suprathermal electrons," IEEE Transactions on Plasma Science, vol. 22, no. 2, pp. 187-198, 1994.

[14] J. K. Hargreaves, The Solar-Terrestrial Environment, Cambridge University Press, Cambridge, UK, 1992.

[15] G. S. Ivanov-Kholodnyi and A. V. Mikhailov, The Prediction of Ionospheric Conditions, Reidel, Dordrecht, The Netherlands, 1986.

[16] W. B. Hanson and R. J. Moffett, "Ionization transport effects in the equatorial F region," Journal of Geophysical Research, vol. 71, pp. 5559-5572, 1966. 

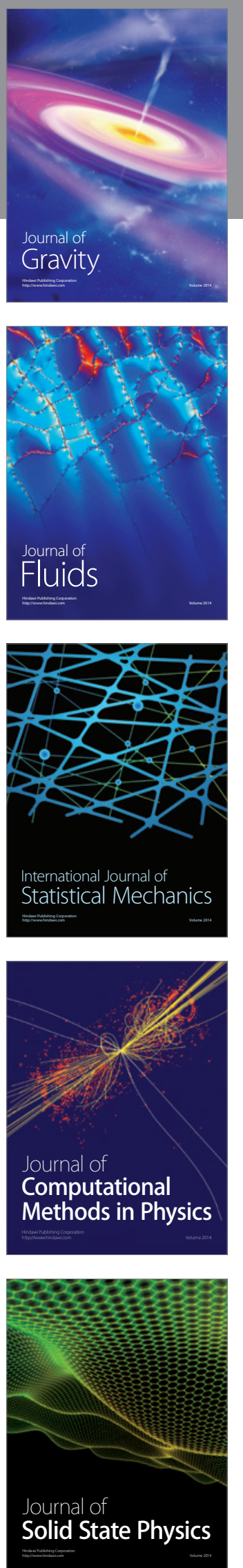

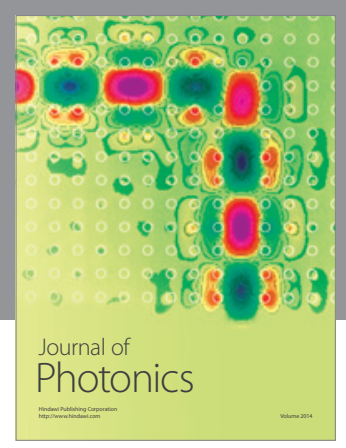

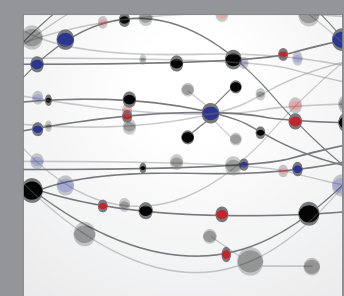

The Scientific World Journal
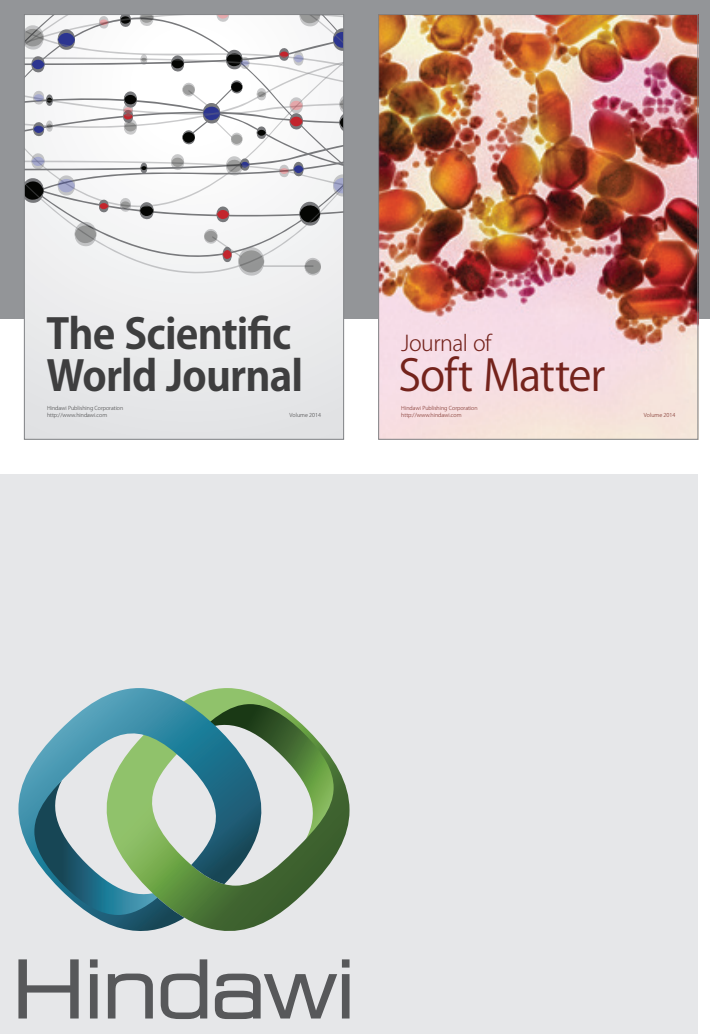

Submit your manuscripts at

http://www.hindawi.com
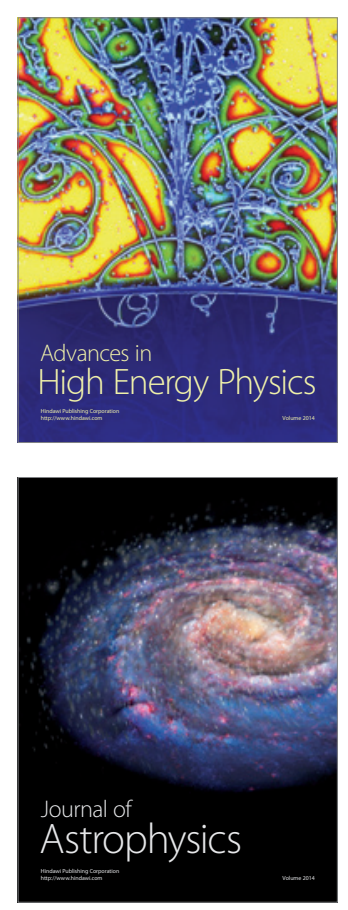
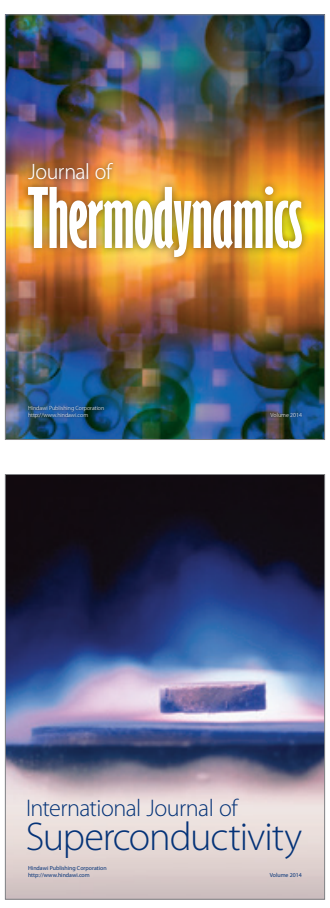
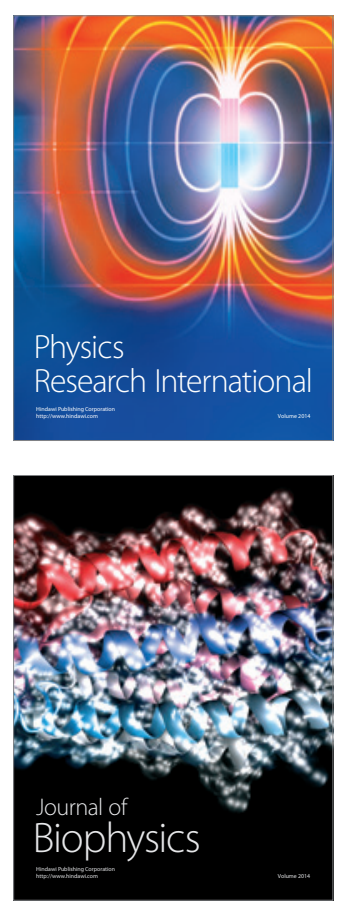
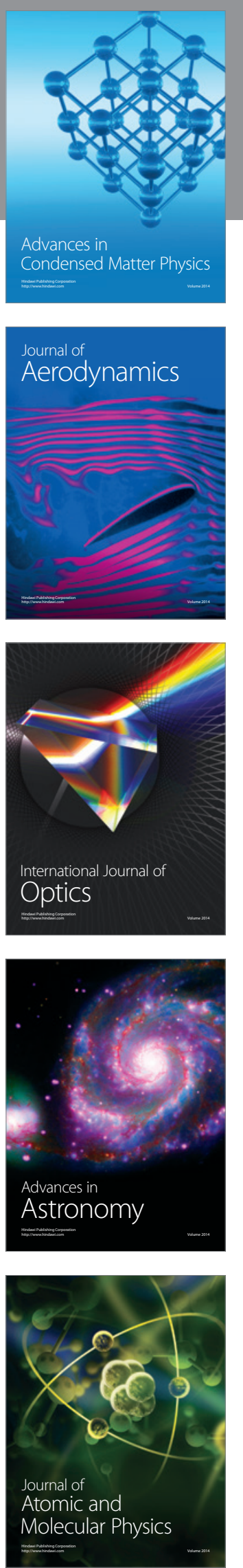